\title{
Ethical IT Behaviour as a Function of Environment
}

\author{
Tony Jewels \\ Queensland University of \\ Technology, Brisbane, Australia
}

\author{
Nina Evans \\ Tshwane University of \\ Technology, Pretoria, \\ South Africa
}

\author{
t.jewels@qut.edu.au
}

\author{
evansa@tut.ac.za
}

\begin{abstract}
Research is currently being undertaken to compare attitudes and behaviour towards ethics in information technology between students at an Australian and a South African university. This work provides a background to ethics from the literature from which a behavioural model for micro-level ethical standards is proposed. Using a theoretical underpinning of Fishbein \& Azjen's Theory of Reasoned Action, a survey document has been developed to identify and compare what constructs most affect an individual's intention to behave in situations requiring ethical considerations.
\end{abstract}

Keywords: Ethical behaviour, Theory of reasoned action, International comparison

\section{Background}

At the 2003 Informing Science conference in Pori, Finland, a South African and an Australian researcher first met and started a conversation about a topic that they are mutually interested in, namely ethical behaviour in the world of Information and Communication Technology (ICT). During the exchange of information about their respective countries and cultures, the topic of the security and crime situation in South Africa took centre stage. When told that South African airport officials search passengers returning from other countries for illegal copies of music CD's and brand name goods as they enter the country, the Australian researcher exclaimed:

"It is ironic that, in a country where people are murdered, hijacked, raped and viciously attacked by the hour, there is still room to worry about ethical issues such as the illegal copying of music CD's!'”

A philosophical question was posed as to what extent ethical IT behaviour might be a function of environment and to what extent the country of origin and residence might influence ethically bound decisions. This question was then specifically related to ethical decisions made by IT students at the universities represented by the two researchers. At that moment a collaborative research project was conceptualised, and now after a visit to Australia and South Africa respectively, this idea will be put into practice with an investigation in both the South African and Aus-

Material published as part of this journal, either on-line or in print, is copyrighted by Informing Science. Permission to make digital or paper copy of part or all of these works for personal or classroom use is granted without fee provided that the copies are not made or distributed for profit or commercial advantage AND that copies 1) bear this notice in full and 2) give the full citation on the first page. It is permissible to abstract these works so long as credit is given. To copy in all other cases or to republish or to post on a server or to redistribute to lists requires specific permission from the publisher at Publisher@InformingScience.org tralian context.

\section{Introduction}

South Africa and Australia are in many ways quite similar; they both have multi-cultural populations, are both in the southern hemisphere, both 
were ruled by Britain for many years, the weather, seasons, plants and flowers are very similar and people from both countries love sport, the outdoors and good food and wine.

Yet, in many other respects, the two countries are worlds apart and this is especially true with their respective safety and security situations. Australia, it must be remembered, was colonised predominantly by British convicts sent to the 'Australian penal colony' in order to overcome the problem of Britain's overcrowded jails, with scant regard given to its existing indigenous population. But whilst still having its own share of crime and violence, these levels pale into relative insignificance when compared to the current levels of crime and violence in South Africa. South Africa has become a country where security companies and security villages in which people are fenced in to keep criminals out, flourish. Vehicle hijacking is common with victims regarding themselves as 'lucky' if they escape from the ordeal alive, but nevertheless remaining highly traumatised. As far as ethics and morality are concerned, South Africa is a 'rudderless ship' where action plans are urgently necessary to prevent further degeneration (Hilliard \& Ferreira 2000). In this environment in which Hilliard and Ferreira (2000) suggest that some people seem to find difficulty distinguishing between ethical and unethical behaviour (moral ambiguity), corruption has become a problem and they believe that the high crime rate is testament to a lack of morality in the country.

One of the main problems in the area of computer ethics is that the general public has not realised the value of ethics and IT security, even though they concern everyone involved in computing (Siponen \& Kajava 1997). In order to reap the benefits of global IT processes such as ecommerce, not only must there be an agreed level of legal certainty and uniformity, as any legal framework can only complement the trust relationship that is at the heart of all commercial transactions (Farhoomand \& Lovelock 2001).

"A code of ethics is necessary to good business in that it allows business transactions to take place in an atmosphere of mutual trust". (Stearns, 1981, p26).

In his work discussing the relationships between international meta-teams Fernandez (2003) suggests that ultimately it is not important what levels of trust exist between various organisations, but that it is important to balance trust against the controls that must be imposed within those relationships. An increased level of control equates to an increased financial overhead (cost), so even a perceived lack of trust within a relationship has the potential to decrease the potential benefit from it.

Aristotle's idea of virtue ethics relies substantially on the effects role models have on people. Aristotle believed that we learn to be moral (virtuous) by modelling the behaviour of moral people and through continual modelling we become virtuous out of habit. People can learn both good and bad habits depending on the role models they have (Blackman \& Leake 2000). The inference is that individuals might adopt the ethical standards consistent within their own social environments and workgroup. The workgroup's ethical behaviour is likely to be influenced by the business organisation's formal and informal ethical practices. Those standards may be influenced by the cultural or political standards practised within an operating region and in turn, regional political morality might be a function of a wider global perspective of what is considered appropriate or acceptable behaviour.

There appears to be little or no research that qualifies or quantifies the effects of each separate group or the effects of multiple group influences but inferential logic would tend to suggest that influence groups may affect ethical IT behaviour as illustrated in Figure 1.

Fishbein and Azjen's Theory of Reasoned Action (TRA) postulates that decisions to take action are influenced by two factors, the first relating to the personal attitude towards the behaviour itself, and the second relating to the perception of how others would evaluate the behaviour. The 
personal attitude, referred to as the outcome evaluation, can be expressed in terms of the sum of an individual's evaluations of the likely outcomes of them undertaking the behaviour. The second attitude can be described more in terms of social pressures expressed in terms of the sum of an individual's perceptions of how influential groups or other individuals weighted with their relative influences on the decision maker, would see the behaviour, (Fishbein \& Ajzen 1975).

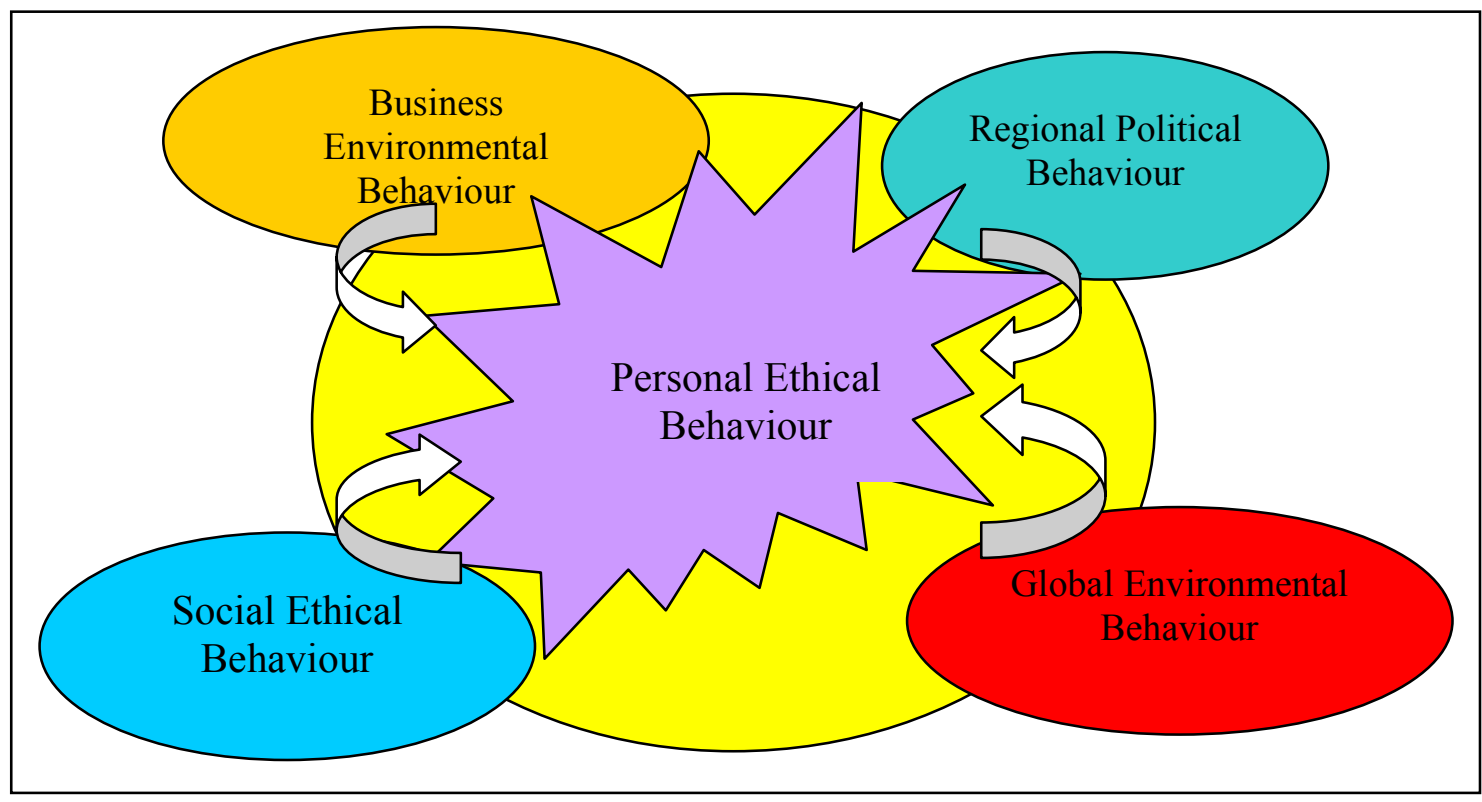

\section{Figure 1 Model of micro-level behaviour (developed with Guido Governatari)}

A survey document has been developed to investigate whether at the university undergraduate level there are differences in the attitudes of South African and Australian students towards ethical computer behaviour. Concurrently it is hoped that this investigation can also be used to quantify the effects of individual influences on 'micro-level' ethical behaviour.

\section{Ethics in ICT}

Computer ethics is one of the most essential areas in (applied) ethics (Gorniak, 1996). Problems such as the lack of laws and security, and the fact that technical knowledge and hardware will constantly increase, demands a new ethical theory to meet the challenges posed by this revolution (Gorniak, 1996; Rogerson, 1996). The definition of 'ethics' as the moral principles governing or influencing conduct (Reader's Digest, 2001) is confirmed by Stearns (1981) as the name given to moral behaviour. Specifically, computer ethics refers to a set of rules or principles used for moral decision making regarding computer technology and computer use (Pierce \& Henry, 1996).

When it comes to computing and business, morals and ethics are interchangeable, with morals originating from the group in which a person matures, and business ethics, by implication, from the group in which your business matures (Middleton, 1999). To what extent, and precisely how, associated groups affect individual ethical IT behaviour is not clearly understood, although there is now a significant body of evidence to suggest that ethical behaviour can be learned. The current literature appears to focus predominantly on the 'role-model' scenario and it is within this framework that this paper will examine the influence of associated group behaviour on the ethical standards of individuals, which we refer to as at a 'micro-level'. 
However claims such as, it is impossible to teach someone morality, because our values are so deeply ingrained (Sojka \& Mickiewicz, 1995) present a somewhat sombre scenario for the future of ethical computing standards, if given credibility. Taking what appears to be a somewhat isolated view of ethical behaviour, Milton Friedman argued from what clearly is a stockholder theory perspective that given its purpose and ownership the sole social responsibility of business was to increase profits and that they should not become involved at all in these matters.

"Such matters are government's role, not business. Managers are agents of owners and should serve these interests" (Friedman, 1970).

Fortunately, such views, although by no means isolated, do not reflect accurately the reality of what Wallace (1996) describes as changing moral values associated with practical knowledge, and he suggests that without such changes in moral values, society might still be accepting of witch trials, judicial torture, slavery and the prohibition of divorce. Business ethics has the potential to become a significant aspect of corporate strategy and culture. Vinten (1998) suggests that we now have the 5Es of audit: economy, efficiency, effectiveness, environment and ethics. He defines the 'business ethics audit' which attempts to find a middle way between a view that businesses are entirely about creating social good, and one which considers that 'the business of business is business' and that there is no wider social responsibility.

The mission statement of computer ethics involves restricting the presence of selfishness or egoism of human nature and enabling harmonious human life in the information technology domain (Siponen, 1997); ethics has somehow to be connected with a human person's well-being and purposes of life (Foot, 1967).

More pragmatically an ethics policy can improve accountability, strengthen morale and performance, and attract more qualified candidates, thus reinforcing brand loyalty, enhancing brand equity and boosting the bottom line (Veit, 2001). In a business environment in which more and more emphasis is being placed on the efficiencies of partnering with other organisations, understanding the nature of win-win propositions and what partnerships really are, becomes a fundamental construct within which trust comes before ethical behaviour (Wilder \& Soat, 2001).

Simon Rogerson, the UK's first professor in computer ethics, states that his overall goal is to integrate computing technology and human values in such a way that the technology advances and protects human values, rather than damages them (Middleton, 1999).

\section{Influences on Micro-level Ethical Behaviour}

\section{Social}

Hollinger (1992) found two variables that were strongly correlated with computer crime, namely friends' involvement and the perceived certainty of being caught. When students in his study reported that none of their best friends had been occasionally involved in piracy, less than 2 percent had committed the act. On the other hand, when more than half of the students' best friends had occasionally committed piracy, almost 40 percent had committed the act themselves. Similarly, about one-third of the students who had more than half their best friends involved in illegal computer account access had engaged in the same activity. Hollinger also found that when the source of social control was university officials, there was a moderately strong, negative relationship between perceived certainty of being caught and frequency of piracy.

Society can't just allow ethics to develop, but must encourage them (Leming, 1993).

"Character develops within a social web or environment. The nature of that environment, the messages it sends to individuals', and the behaviours it encourages and discourages 
are important factors to consider in character education. Clear rules of conduct, personal ownership of those rules, a supportive environment, and satisfaction resulting from complying with the norms of the environment are what shape behaviour."

Leming stresses that people must not only get good social rewards for doing the right thing, but they must never get negative social feedback for a desirable action.

\section{Business}

There are wide ranging views of what should be termed ethical behaviour at the organisation level. Friedman's (1970) views are in contrast with the more current thoughts of Thomas Donaldson, a legal studies professor at the Wharton School of Business at the University of Pennsylvania, who states that there are three ethics compliance programs corporations can implement:

- Code and compliance regulating employee behaviour;

- Identity and values that speak what the company stands for; and

- Social outreach or "social accounting" activities demonstrating ethical conduct even in the face of a loss of profit. (Veit, 2001)

An article by McDonald and Zepp (1990) looks at practical ways for managers to establish ethical priorities at the same three levels: an individual level, a group level and an organisational level. The issue of the personal values and motives of the organisational founders and other organisational leaders is considered by Dickson, Smith, Grojean and Ehrhart (2001) who argue that the organizational climate regarding ethics, the shared perception of what is ethically correct behaviour and how ethical issues should be handled within an organization, is influenced by the legacy of these pioneers. When a situation is ambiguous, and referents (peers, or the informal code of behaviour) clarify the ambiguity, field dependent individuals (sometimes called organizationally dependent) use the referents to guide behaviour and decisions (Witkin \& Goodenough, 1977).

\section{Regional Political}

Aristotle argued that the 'state' functions to enable people (a collective) to share ideas and agree on a common code of what might be termed 'acceptable behaviour'. People are social creatures; that is there is a natural characteristic to live in a state. Socrates (circa 469-399 BC) differentiated between the law and morality; the state might legislate on right and wrong behaviour but every citizen should be vigilant in keeping under review what is accepted as moral opinion, (Jarvis, 2000).

Global technologies, such as the Internet, have a large spread of users from different countries, cultures and sub-cultures. Although cultural differences cannot be classed as problems as such, we can identify them as one factor within many, which influence global technologies. Tackling problems with global technology requires however a global approach. Within Australia we have seen an excellent example of a government not understanding this fundamental with the Australian government's attempts to regulate some of the more seedy aspects of the Internet, drawing international criticism for their lack of understanding of the technology. It is considered not possible to enact effective laws or to provide ethical guidance to an international community without an international method (Blackman \& Leake, 2000). 


\section{Global}

A shrinking world and technological progress mean that problems are increasingly global and demand solutions that presuppose a framework of values acceptable everywhere. In his book 'Shared Values for a Troubled World', Kidder (1994) identifies eight shared values:

- Love

- Truthfulness

- Fairness

- Freedom

- Unity

- Tolerance

- Responsibility

- Respect for life

Global ethics is a concept that has been well-developed and well-documented internationally as the universal standards and norms that are internationally accepted by both the secular and religious community. Hilliard and Ferreira (2000) in this regard, cite Kung (1997) as referring to 'core morality'.

\section{Research Method}

\section{Theory of Reasoned Action}

First developed in 1967 the original theory of reasoned action (TRA) was expanded by Fishbein and Ajzen (1975) to provide a framework in which to study attitudes towards behaviours.

The components within TRA consist of

Behaviour - defined by a combination of four components

- Action

- Target

- Context

- Time

Intention - a propensity to act as a function of two determinants

- Attitude toward performing in a certain way, based on its perceived consequences

- Perception of the social (normative) pressure to perform in a particular way by 'relevant' others.

TRA appears to be a successful indicator and predictor of behaviour when it is applied to behaviours that are under a person's volitional control. But wherever the individual is, due to intervening, environmental conditions, prevented from performing the behaviour, even though they may be motivated by their own attitudes and by subjective norms to do so, they may not actually perform the behaviour. To allow for this phenomenon, Ajzen subsequently added a third component to the original TRA that he called the concept of 'perceived behavioural control' which led to a newer theory known as the 'Theory of Planned Behaviour', (TPB) (Ajzen, 1991).

Perceived behavioural control is itself determined by two components: 
- Control Beliefs - the motivation to behave in a particular manner, influenced by the perception of how difficult the behaviour is likely to be.

- Perceived Power - the motivation to behave in a particular manner, influenced by the perception of how successful that behaviour is likely to be.

These perceptions can be reflected from past experiences, from an anticipation of future circumstances, or from the attitudes of cultural norms that surround the individual, (Mackenzie \& Jurs, 1993). The idea is similar to that espoused by Lewin (1952) who suggests that actions are not taken by an individual without taking into account the domain in which the action is being taken and the psychological field at any given point in time.

Two assumptions that underline both these theories are that

- Humans are rational beings that are able to process and use information in order to make systematic use of it.

- Humans will consider the implications of their actions before undertaking certain behaviours.

For the purpose of this study however, as we are investigating only the intentions to behave and not the behaviour itself, we intend initially to apply the original Theory of Reasoned Action and to concomitantly investigate environmental factors that might contribute to an individual's perception of lack of volitional control.

\section{Survey Design}

The purpose of the survey is to investigate subject's behavioural intentions for a range of issues requiring ethical considerations. It is intended to compare the responses of $3^{\text {rd }}$ year undergraduates from a South African university with those of $3{ }^{\text {rd }}$ year undergraduates from an Australian university. It was considered that students about to graduate would have been likely to have been already exposed to ethical values within the university environment as well as some being exposed to ethical realities within a business environment through part time positions.

A variation to the Theory of Reasoned Action is adopted as the research is also interested in investigating the impact of the four individual influences described in our proposed model:

- Social/Family

- Business/University

- Regional Political

- Global

It is in the social (normative) perception part of TRA, referring to 'relevant others' that this research varies from the more traditional TRA approach. Rather than simply refer to the homogenous 'relevant others' we attempt to distinguish between the different types of relevant other. An example of the traditional two part TRA question normally asked is of the type:

1) My unauthorised copying of music CD's is acceptable Strongly agree[ ] Agree[ ] Undecided[ ] Disagree[ ] Strongly disagree[ ]

2) Other people would condone my unauthorised copying of music CD's Strongly agree[ ] Agree[ ] Undecided[ ] Disagree[ ] Strongly disagree[ ] 
The modified TRA survey attempts to distinguish between the different 'others' by referring to each influence and the strength of that influence towards the behaviour.

1) My unauthorised copying of music CD's is acceptable Strongly agree[ ] Agree[ ] Undecided[ ] Disagree[ ] Strongly disagree[ ]

2a) My family/friends would condone my unauthorised copying of music CD's Strongly agree[ ] Agree[ ] Undecided[ ] Disagree[ ] Strongly disagree[ ]

2b) My fellow students/workers would condone my unauthorised copying of music CD's Strongly agree[ ] Agree[ ] Undecided[ ] Disagree[ ] Strongly disagree[ ]

2c) My fellow countrymen/citizens would condone my unauthorised copying of music CD's Strongly agree[ ] Agree[ ] Undecided[ ] Disagree[ ] Strongly disagree[ ]

2d) The rest of the world would condone my unauthorised copying of music CD's Strongly agree[ ] Agree[ ] Undecided[ ] Disagree[ ] Strongly disagree[ ]

3a) My family and friend's opinion is important to me Strongly agree[ ] Agree[ ] Undecided[ ] Disagree[ ] Strongly disagree[ ]

3b) My fellow students/workers opinion is important to me Strongly agree[ ] Agree[ ] Undecided[ ] Disagree[ ] Strongly disagree[ ]

3c) My fellow countrymen/citizens opinion is important to me Strongly agree[ ] Agree[ ] Undecided[ ] Disagree[ ] Strongly disagree[ ]

3d) The rest of the world's opinion is important to me Strongly agree[ ] Agree[ ] Undecided[ ] Disagree[ ] Strongly disagree[ ]

The survey instrument covers the following behaviours

1. Copying unauthorised music CD's

2. Copying unauthorised software

3. Application eg MS Office

4. Operating System eg MS Windows

5. Only for study purposes ....

6. Unauthorised access to other peoples files/data

7. Reading data from such unauthorised access

8. Sharing data from such unauthorised access

9. Modifying data from such unauthorised access

10. Using other peoples work without giving them credit for the idea (plagiarism)

11. Adding your name to a group assignment without contributing your fair share ('piggybacking')

12. Distribution of harmful, destructive software (eg viruses)

13. Stealing computer hardware

Although the survey responses will remain strictly anonymous the following demographics will be collected.

1. Gender 
2. Specialisation e.g. IS/Computer Science/Data Communications/Business Applications/Web Development/Communication Networks

3. Age

4. Country of Birth

5. Work experience

a. Any Work experience $\mathrm{Y} / \mathrm{N}$

i. IT working experience $\mathrm{Y} / \mathrm{N}$

ii. Number of years in IT ....

\section{Summary}

The mere fact that ethical standards are continually changing, reflected in the changing perspective of various levels of societal groups within an ever developing technological framework makes the creation of a static universal code of behaviour virtually impossible. Even if such a code of behaviour could be created it would be in practical terms irrelevant without global acceptance and conformity. Morality is a human creation that changes through time Wallace (1996).

South Africa is currently in a transitional situation where many of the ethical values and norms based on Christian principles are now being seriously questioned, due to a mistrust of the 'old ways' Hilliard and Ferreira, (2000). This research sets out to investigate whether there are now differences in ethical standards between students that are part of such a society and students that are not. There are likely to be significant implications for any society that is even perceived by the rest of the world to have a different set of ethical values.

\section{References}

Ajzen, I. (1991). The theory of planned behaviour. Organizational Behaviour and Human Decision Processes, 50, 179-211.

Blackman, D., \& Leake, M. (2000). Towards a universal world of computer ethics. Paper presented at the AiCE2000 CONFERENCE on Computer Ethics, ANU Canberra.

Dickson, M. W., Smith, D. B., Grojean, M. W., \& Ehrhart, M. (2001, Summer). An organizational climate regarding ethics: The outcome of leader values and the practices that reflect them. Leadership Quarterly, 12, 197-217.

Farhoomand, A., \& Lovelock, P. (2001). Global E-commerce: Text and cases. Singapore: Prentice Hall.

Fernandez, W. D. (2003). Metateams in major information technology projects: A grounded theory on conflict, trust, communication, and cost. Unpublished PhD Thesis, Queensland University of Technology, Brisbane.

Fishbein, M., \& Ajzen, I. (1975). Belief, attitude, intention and behaviour: An introduction to theory and research. Boston MA: Addison-Wesley.

Foot, P. (1967). Moral belief. In P. Foot (Ed.), Theories of ethics. Oxford: Oxford University Press.

Friedman, M. (1970, 13 September). The social responsibility of business is to increase its profits. New York Sunday Times Magazine, 13, 32.

Gorniak, K. (1996). The computer revolution and the problem of the global ethics. Science and Engineering Ethics, 2 (2).

Hilliard, V. G., \& Ferreira, I. W. (2000). Global ethics for South Africa. Paper presented at the Conference on Ethics2000: Dimensions of Ethics in the New Millennium, Oregon, USA. 


\section{Ethical IT Behaviour as a Function of Environment}

Hollinger, R. C. (1992). Crime by computer: Correlates of software piracy and unauthorized account access. Security Journal, 2 (1), 2-12.

Jarvis, C. (2000). Business Ethics Resources, Retrieved from http://sol.brunel.ac.uk/ jarvis/bola/ethics/whatis.html

Kidder, R. M. (1994). Shared values for a troubled world: Conversations with men and women of conscience. San Francisco: Jossey-Bass Publishers.

Kung, H. (1997). A global ethic for global politics and economics. New York NY: Oxford University Press.

Leming, J. S. (1993). In search of effective character education. Educational Leadership Magazine, 51 (3), 63-71.

Lewin, K. (1952). Field theory in social science. London: Tavistock Publications.

Mackenzie, J. F., \& Jurs, J. L. (1993). Planning, implementing, and evaluating health promotion programs: A primer. New York: Macmillan.

McDonald, G. M., \& Zepp, R. A. (1990). What should be done? A practical approach to business ethics. Management Decision, 28 (1).

Middleton, C. (1999, January). Ethics man. Business and Technology, 22-27.

Pierce, M. A., \& Henry, J. W. (1996). Computer ethics: The role of personal, informal, and formal codes. Journal of Business Ethics, 15 (4), 425.

Reader's Digest. (2001). Reader's Digest Wordpower Dictionary. Turnhout, Belgium: Reader's Digest Association.

Rogerson, S. (1996). The ethics of computing: The first and second generation. The Business Ethics Network New (6).

Siponen, M. T. (1997). The applicability of ethical theories to computer ethics - Selected issues.Unpublished manuscript, UK.

Siponen, M. T., \& Kajava, J. (1997). Computer ethics - the most vital social aspect of computing: Some themes and issues concerning moral and ethical problems of IT. Paper presented at the IRIS 20, Hanko, Norway.

Sojka, J., \& Mickiewicz, A. (1995, 1 February). Developing business and computer ethics in Poland - a choice of strategy. Paper presented at the Computer Ethics Conference, Leicester, UK.

Stearns, M. (1981). What are business ethics? Data Management, 19 (5), 26.

Veit, L. (2001). Ethical matters. Credit Union Management, 24 (6), 18-20.

Vinten, G. (1998). Putting ethics into quality. The TQM Magazine, 10, 89-94.

Wallace, J. D. (1996). Ethical norms, particular cases. Ithaca: Cornell University Press.

Wilder, C., \& Soat, J. (2001, Jul 30). The trust imperative. Informationweek, 34.

Witkin, H. A., \& Goodenough, D. R. (1977). Field dependence and interpersonal behavior. Psychological Bulletin, 84, 661-689. 


\section{Biographies}

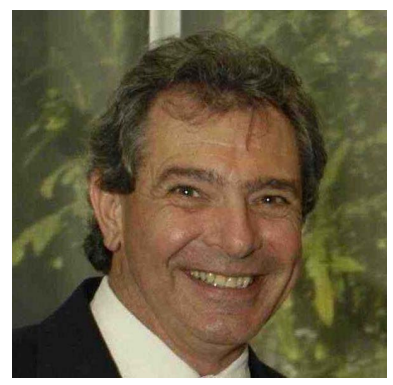

Tony Jewels is a lecturer within the School of Information Systems at Queensland University of Technology, Brisbane, coordinating IT project management units. An IT professional for over 30 years, he has worked in a variety of roles on many leading edge projects throughout the world. His practical experience combined with academic qualifications in business management and information technology provides students at both undergraduate and postgraduate level with real world perspectives of life within the IT sector.

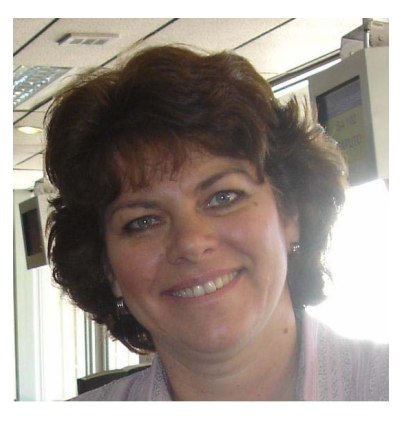

Nina Evans currently manages the academic programs and personnel of the Business Applications and IT Management department in the faculty of ICT of Tshwane University of Technology, Pretoria. The focus areas of the department are business analysis, project management, business information systems, knowledge management, ecommerce, business management, and personal and professional development of IT students/ employees, IT management and strategic management. She also lectures in the fourth year subjects on Business Management, Business Fundamentals, Information and Technology Management and Strategic Information Systems. 